\title{
European Geriatric Medicine: building our journal together
}

\author{
Alfonso J. Cruz-Jentoft ${ }^{1}$
}

Published online: 4 January 2018

(C) European Geriatric Medicine Society 2017

The European Geriatric Medicine Society (EUGMS, originally European Union Geriatric Medicine Society, now recently renamed) is a young organization. It was born in 2000 and, in its short life, has been able to become the preferred hub for European geriatricians [1]. The yearly congress has grown steadily, and in recent years it attracts participants from all continents (every five congress delegates are non-Europeans).

A modern scientific society needs a strong journal. Initially, EUGMS affiliated with the Journal of Nutrition, Health and Aging. However, by 2010, it became evident that a European based journal focused on Geriatric Medicine and managed directly by the EUGMS was needed. European Geriatric Medicine was, therefore, launched; Prof. Jean-Pierre Michel was appointed Editor-in-Chief and Elsevier was chosen as the publisher.

Starting a new scientific journal from scratch was a major challenge. Prof. Michel was very successful in coping with it [2]. In the last 8 years EGM has received almost 2000 manuscripts from around the world, the number increasing steadily, so the acceptance rate is now below $50 \%$. The number of non-European articles has also increased to around $50 \%$ of the submissions. EGM was impressively fast in receiving an impact factor-achieved in 2012, after just 2 years. The impact factor reached 1.336 in 2016, which is quite impressive for a journal that is not yet listed in Medline. EGM is now a widely recognized and read journal around the world.

Even though the journal has had positive results, wanting to always improve it, the EUGMS thought it was time for a change: one of the most prestigious medical publishers, Springer Nature, agreed to take over the journal. Prof. Michel decided to step down, and the EUGMS Executive Board asked me to become Editor-in-Chief. In recognition of his essential role in the launch and

Alfonso J. Cruz-Jentoft

alfonsojose.cruz@salud.madrid.org; editoregm@gmail.com

1 Jefe del Servicio de Geriatría, Hospital Universitario Ramón y Cajal (IRYCIS), Madrid, Spain consolidation of European Geriatric Medicine, Prof. Michel has been appointed Honorary Editor. European Geriatric Medicine is now entering a new stage, with major changes that will be gradually implemented over the next few years.

Some decisions have had to be made at this point. The first was the business model: the EUGMS was certain that publication of articles in the journal had to be free of charge for authors. Institutions and individuals (who are not members of the EUGMS) will have to subscribe to the journal to read the full content of the articles, which is common for the most prestigious medical journals. If authors want to have their articles freely available, they may publish with the Open Access model that is now customary in most journals.

A second major change is that EGM will be fully electronic: it will not be published in paper any more. We feel that this is where most journals are moving, for many reasons including practical, ecological, organizational and financial ones. Fortunately, this will allow electronic access to be granted to all members of the EUGMS through the society's website, and thus increase dissemination of the journal in Europe.

The Instructions for Authors have also been re-written, with a reduction in the number and types of articles accepted: original research, brief reports, reviews, special articles, editorials and letters to the editor. The focus will always be on Geriatric Medicine in any care setting-not basic research or gerontology-, including articles on comprehensive geriatric assessment, geriatric syndromes, geriatric education, old age psychiatry, models of geriatric care in health services, and quality assurance. There are some areas of Geriatric Medicine that will be specially favoured as main focus areas of EUGMS: appropriate research and use of drugs in older people, cardiovascular Geriatric Medicine, sarcopenia and frailty, neurodegenerative diseases, and end of life care for older people, while functionality in old age will be the underlying thread. Professors Cherubini, Strandberg, Arai, Roberts and Crome have been appointed Associate Editors to manage each of these areas. A new Editorial Board will be also appointed, 
with an increased focus on non-European countries to better reach authors from these countries.

We have high expectations of our collaboration with Springer. We will work with them in reducing the response time and improving the authors' publication experience. The team assigned to launch the new journal is composed of excellent professionals and good team workers. Of course, the first hurdle to jump will be gaining access to Medline, an essential step to increase the visibility of EGM. We are confident we will be able to do it in the nottoo-distant future.

European Geriatric Medicine is the journal of EUGMS and thus of all European geriatricians. It needs the strong support of all, especially of the academic and research centres, if it is to become a reference journal in Geriatric Medicine. We do expect an increasing involvement and cooperation of all EUGMS members in reading the journal, citing it, submitting some of their high quality research, and writing good and fast reviews when asked. EGM is our journal: we need to build it together, to team together (geriatricians feel proud of being able to work in teams) to warrant success of this new stage of European Geriatric Medicine.

\section{Compliance with ethical standards}

Conflict of interest The author declares that he has no competing interest.

\section{References}

1. Baeyens JP, Cruz-Jentoft AJ, Cherubini A (2010) The success story of the European Union Geriatric Medicine Society (EUGMS). Eur Geriatr Med 1(2):137-140

2. Michel J (2017) Being editor in chief: a great experience gives way to a smooth transition. Eur Geriatr Med. https://www.sciencedir ect.com/science/article/pii/S1878764917301717 (in press) 